\title{
Temporary Left Ventricular Pacing: A Desperate Life-saving Measure in Emergency Situation
}

\author{
Ajaz Ahamad Lone, Mohd Iqbal Dar, Fayaz Ahamad Rather, Mohd Sultan Alai, Imran Hafiz, Jahangir Rashid Beigh \\ Department of Cardiology, SKIMS, Srinagar, Jammu and Kashmir, India
}

\section{Abstract}

Transcutaneous or transvenous pacing of the right ventricle is performed as a routine practice for patients received with symptomatic bradycardia or complete heart block with relative ease in cath lab. However, more and more patients are received with multiple comorbidities, critical condition, and difficult vascular access. In this article, we describe a patient with difficult venous access with tricuspid regurgitation and displaced the right ventricular pacemaker temporary lead undergoing coronary angiography who was managed with emergent nonconventional left ventricular pacing.

Keywords: Heart block, temporary pacing, transvenous pacing

\section{INTRODUCTION}

Among the cardia rhythm disturbances bradyarrythmias are more commonly encountered and have life threatening presentations. Prompt treatment of the condition has a rewarding out come in these patients.

\section{Case Report}

A 68-year-old male with hypertension presented with episodes of recurrent syncope with ECG showing complete heart block [Figure 1]. In addition, the patient has a history of angina and doubtful history of a previous myocardial infarction.

The patient was stabilized by putting in temporary pacemaker lead through the left femoral vein as the right femoral venous puncture could not be done despite multiple attempts. Echocardiography showed low left ventricular (LV) systolic ejection functions and tricuspid regurgitation. The patient was further planned for coronary angiography for accessing the status of coronaries which revealed severe multivessel coronary artery disease [Figures 2 and 3].

Immediately after completing the coronary imaging, the patient developed intermittent capture loss of temporary pacemaker, manipulation of the temporary lead proved to be difficult, and the patient developed asystole [Figure 4] and was unresponsive despite multiple attempts of lead manipulation.

\begin{tabular}{|l|l|}
\hline \multicolumn{3}{|c|}{ Access this article online } \\
\hline Quick Response Code: & Website: \\
\hline & www.ijccm.org \\
\hline
\end{tabular}

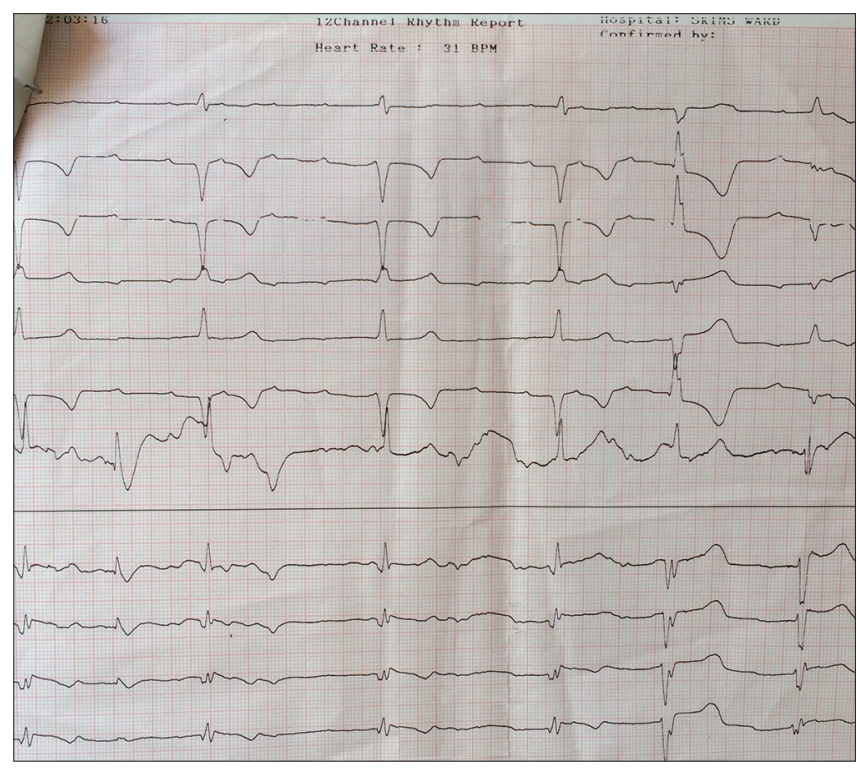

Figure 1: ECG showing complete hear block

Address for correspondence: Dr. Mohd lqbal Dar, Department of Cardiology, SKIMS, Soura, Srinagar - 190010 , Jammu and Kashmir, India. E-mail: darmohdiqbal@yahoo.in

This is an open access article distributed under the terms of the Creative Commons Attribution-NonCommercial-ShareAlike 3.0 License, which allows others to remix, tweak, and build upon the work non-commercially, as long as the author is credited and the new creations are licensed under the identical terms.

For reprints contact: reprints@medknow.com

How to cite this article: Lone AA, Dar MI, Rather FA, Alai MS, Hafiz I, Beigh JR. Temporary left ventricular pacing: A desperate life-saving measure in emergency situation. Indian J Crit Care Med 2017;21:531-3. 
Cardiopulmonary resuscitation was started, and atropine and adrenaline infusion started, but no rhythm could be established. As a desperate last-ditch effort, a second 6F temporary lead was advanced through femoral artery sheath into LV apex and pacing commenced at higher threshold [Figure 5].

Within a few moments, hemodynamics improved and the patient became responsive. The right pacemaker lead was then successfully negotiated in the right ventricular (RV) apex, and parameters checked followed by taking out of LV lead. The patient was shifted to the intensive care unit in a stable condition and underwent permanent pacemaker implantation subsequently.

\section{DisCussion}

Complete heart block has a high mortality with 1-year survival of $68 \%$ and 5 -year survival of $37 \%$. ${ }^{[1]}$ Temporary transvenous pacing (TVP) is a routine emergency intervention used primarily to correct profound bradycardia with associated hemodynamic compromise which is unresponsive to transcutaneous pacing or drug therapy. It involves stimulation of the endocardial surface

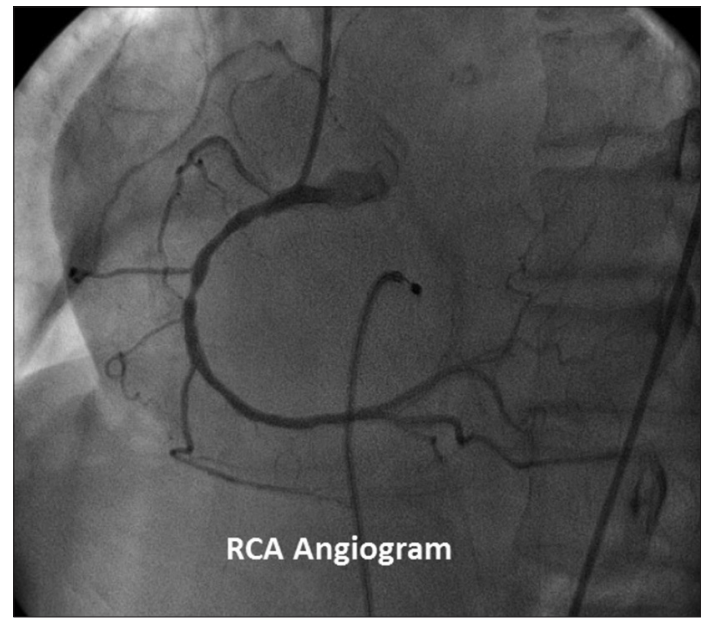

Figure 2: Right coronary angiogram

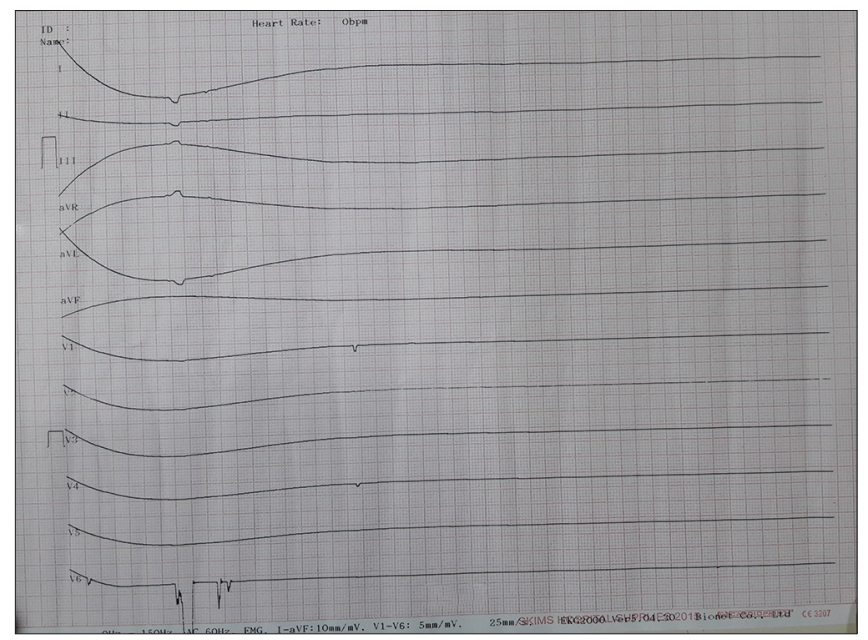

Figure 4: ECG showing asystole of the RV apex using an electrode-tipped temporary pacing lead which is passed through a large central vein sheath. Temporary TVP can be used as a bridge to permanent pacemaker insertion or till correction of hyperkalemia causing symptomatic bradyarrhythmia. The usual success rate of temporary TVP is around 95\%. ${ }^{[2]}$ As the survival of patients improves in various comorbidities due to the advancement of medical care, more and more patients are received with difficult venous access. Many uncommon approaches have been discussed in literature in specific condition such as pacing through coronary sinus in RV infarction, sever TR, and compromised venous accesses..$^{[3,4]}$ During cardiac surgery, the placement of epicardial leads is an established technique. ${ }^{[5]} \mathrm{A}$ few reports mention pacing through guidewire placed in septal coronary artery during PCI and other involves LV pacing with BMW guidewire placed in LV apex. ${ }^{[6]}$

\section{Conclusion}

Our innovative technique can prove a life-saving measure in a desperate situation when the conventional measures fail. It may be useful to have knowledge of this procedure as a backup measure.

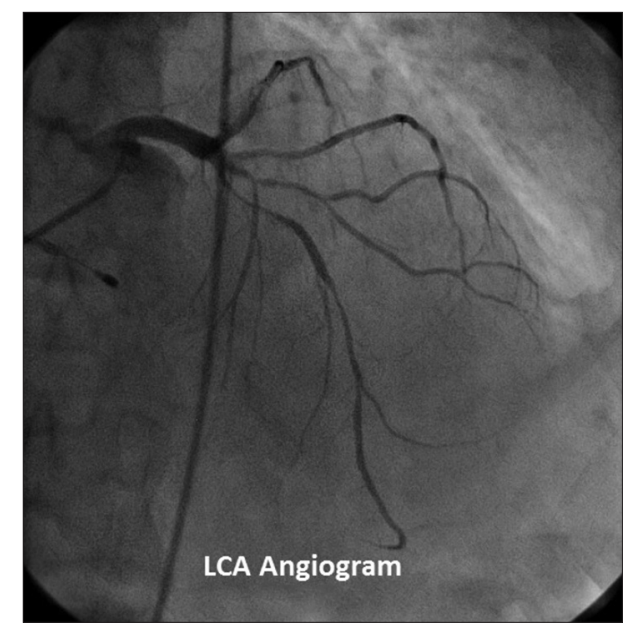

Figure 3: Left coronary angiogram

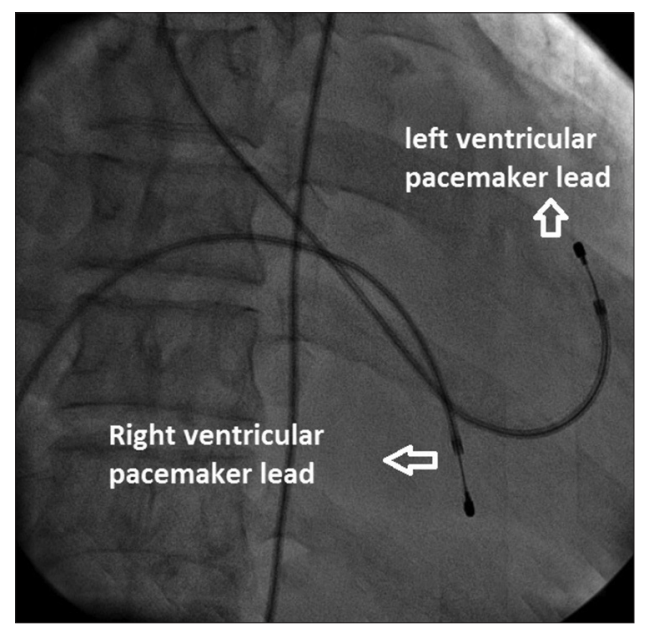

Figure 5: Pacemaker lead in left ventricle 


\section{Financial support and sponsorship}

Nil.

\section{Conflicts of interest}

There are no conflicts of interest.

\section{References}

1. Edhag O, Swahn A. Prognosis of patients with complete heart block or arrhythmic syncope who were not treated with artificial pacemakers. A long-term follow-up study of 101 patients. Acta Med Scand 1976;200:457-63.

2. Hynes JK, Holmes DR Jr., Harrison CE. Five-year experience with temporary pacemaker therapy in the coronary care unit. Mayo Clin Proc 1983;58:122-6.

3. Gilchrist IC, Cameron A. Temporary pacemaker use during coronary arteriography. Am J Cardiol 1987;60:1051-4.

4. McNulty PH, Rice KS, Saraiya RB, McCann J, Ettinger SM, Gilchrist IC, et al. Usefulness of temporary left ventricular pacing through the coronary sinus as an adjunct to transfemoral percutaneous coronary intervention. Am J Cardiol 2004;94:1055-7.

5. Flynn MJ, McComb JM, Dark JH. Temporary left ventricular pacing improves haemodynamic performance in patients requiring epicardial pacing post cardiac surgery. Eur J Cardiothorac Surg 2005;28:250-3.

6. Ali F, Mohamad T, Elder M, Jacob S, Gardi DO. Left ventricular "Temporary Pacemaker Wire": A viable option in emergency situation. Am J Emerg Med 2009;27:374.e1-74.e2. 